\title{
Topical tranexamic acid in hip fractures: a randomized, placebo-controlled double-blinded study
}

\author{
Darren Costain, MD, MSc \\ Graham Elder, MD CM \\ Brian Fraser, MD \\ Brad Slagel, MD \\ Adrienne Kelly, MD \\ Yifun Cheong, MD \\ Luke Fera, MD, MSc
}

Accepted Oct. 28, 2020

\author{
Correspondence to: \\ D. Costain \\ Northern Ontario School of Medicine \\ Division of Orthopedic Surgery \\ Sault Area Hospital \\ 955 Queen St E, Suite 100 \\ Sault Ste. Marie ON P6A 2C3 \\ dcostain@gmail.com
}

DOI: $10.1503 /$ cjs. 014220

\begin{abstract}
Background: Tranexamic acid (TXA) has been shown to reduce perioperative blood loss in elective orthopedic surgery. The safety of intravenous TXA in nonelective hip fracture surgery is uncertain. The purpose of this study was to evaluate the efficacy and safety of topical TXA in hip fracture surgery.
\end{abstract}

Methods: Adult patients presenting to a community hospital with a hip fracture requiring surgery were randomly assigned to receive topical TXA or placebo. Hemoglobin and troponin I levels were measured preoperatively and on postoperative days 1,2 and 3. All postoperative blood transfusions were recorded. Complications, including acute coronary syndrome (ACS), venous thromboembolism (VTE), cerebrovascular accidents (CVA), surgical site infections (SSI) and 90-day mortality, were recorded.

Results: Data were analyzed for 65 patients (31 in the TXA group, 34 in the control group). Hemogloblin level was significantly higher on postoperative days 1 and 2 in the TXA group than in the control group. The difference in hemoglobin level between the groups was not statistically significant by postoperative day 3. Significantly fewer units of packed red blood cells were transfused in the TXA group ( 2 units v. 8 units); however, 2 of the units in the control group were given intraoperatively, and when these were excluded the difference was not significant. The incidence of ACS, CVA, VTE, SSI, transfusion and all-cause mortality at 90 days did not differ significantly between the groups.

Conclusion: Topical TXA reduces early postoperative blood loss after hip fracture surgery without increased patient risk. Trial registration: Clinicaltrials.gov, no. NCT02993341.

Contexte : L'acide tranexamique (TXA) a permis de réduire les pertes sanguines périopératoires lors de chirurgies orthopédiques non urgentes. On ne connaît pas précisément l'innocuité du TXA lors de chirurgies urgentes pour fracture de la hanche. Cette étude avait pour but d'évaluer l'efficacité et l'innocuité du TXA topique lors de chirurgies pour fracture de la hanche.

Méthodes : Des patients adultes ayant consulté dans un hôpital communautaire pour une fracture de la hanche nécessitant une chirurgie ont été assignés aléatoirement soit au TXA topique, soit à un placebo. Les taux d'hémoglobine et de troponine I ont été mesurés avant, puis 1,2 et 3 jours après l'intervention. Toutes les transfusions sanguines ont été consignées, ainsi que les complications, telles que le syndrome coronarien aigu (SCA), la thromboembolie veineuse (TEV), l'accident vasculaire cérébral (AVC), l'infection de la plaie opératoire et la mortalité à 90 jours.

Résultats : Les données ont été analysées pour 65 patients (31 dans le groupe sous TXA et 34 dans le groupe témoin). Le taux d'hémoglobine était significativement plus élevé aux jours postopératoires 1 et 2 dans le groupe sous TXA que dans le groupe témoin. La différence de taux d'hémoglobine entre les groupes n'était plus statistiquement significative au $3^{\mathrm{e}}$ jour postopératoire. Un nombre significativement moindre d'unités de culots globulaires ont été administrées dans le groupe TXA (2 unités c. 8 unités); par contre, 2 des unités dans le groupe témoin ont été administré pendant l'intervention, et lorsqu'elles ont été exclues, la différence n'était plus significative. L'incidence des SCA, des AVC, des TEV, des infections de plaies, des transfusions et de la mortalité de toute cause à 90 jours n'a pas été significativement différente entre les 2 groupes.

Conclusion : Le TXA topique réduit les pertes sanguines durant la période postopératoire immédiate après la chirurgie pour fracture de la hanche, sans exposer les patients à un risque accru. Numéro d'enregistrement de la recherche : ClinicalTrials.gov, no. NCT02993341. 
A pproximately 26000 Canadians experience hip fractures each year, ${ }^{1}$ with just under 4500 cases per year requiring hemiarthroplasty. ${ }^{2}$ We know from multiple studies that hip fractures carry a substantial risk of perioperative and postoperative mortality of approximately $10 \%$ at 1 month and $25 \%$ at 1 year..$^{3-6}$ Preoperative anemia is common, as is perioperative blood loss, leading to allogeneic blood transfusion rates of $40 \%-59 \%$ in this population..$^{7-9}$ Blood transfusions are not a benign treatment; infection, length of hospital stay and mortality are all increased by exposure to allogeneic blood..$^{10}$ Further, postoperative anemia is felt to increase cardiac strain and reduce early mobility, both undesirable in the frail elderly postoperatively. Mechanisms by which to reduce perioperative blood loss are therefore of potential financial and clinical benefit in the hip fracture population. Tranexamic acid (TXA) is an inexpensive medication (institutional cost of $\$ 4.69 / \mathrm{g}$ at the time of manuscript submission). The use of intravenous TXA reduces blood loss in hip fracture surgery, although it has been associated with higher morbidity and mortality in some studies. ${ }^{11-13}$ Topical TXA has been shown to reduce blood loss following total joint arthroplasty, ${ }^{14-17}$ and systemic TXA levels are low with topical TXA administration compared with intravenous administration, ${ }^{18}$ suggesting that topical TXA is a safe alternative to intravenous TXA in hip fracture surgery. The purpose of this study was to evaluate the efficacy and safety of topical TXA with hip fracture surgery.

\section{Methods}

Consecutive patients presenting to our community hospital between November 2017 and February 2019 with hip fracture requiring surgery were invited to participate in the study. Inclusion criteria were hip fracture requiring surgery, age older than 18 years and provision of written informed consent by the patient or a surrogate decisionmaker. Exclusion criteria were documented renal failure (glomerular filtration rate $<30 \mathrm{~mL} / \mathrm{min}$ per $1.73 \mathrm{~m}^{2}$ ), allergy to TXA, acute coronary syndrome (ACS) within 6 months of fracture, any history of deep vein thrombosis (DVT) or venous thromboembolism (VTE), current hormone replacement therapy, acquired disturbance of colour vision, refusal of allogeneic blood or blood products, use of anticoagulants within 5 days of fracture, preexisting fibrinolytic disorder or known coagulopathy (including platelet count below $150 \times 10^{9} / \mathrm{L}$ ), gross hematuria, pregnancy or lactation, or major psychiatric disorder that might interfere with study participation. The Research Ethics Board of The Group Health Centre and Sault Area Hospital and Health Canada granted approval of this study. Written informed consent was obtained from all study participants or their proxy decision-maker. The study was registered in the public registry ClinicalTrials.gov (NCT02993341).
All patients had baseline hemoglobin and troponin I levels measured. Participants were randomly allocated to a treatment group using Graphpad Prism, which creates an equally divided treatment algorithm generated using the time of day to create the first random number. The pharmacy technician was privy to the treatment allocation, and treatment group allocation was maintained in a secure binder in the pharmacy. The medication was delivered to the operating theatre with the patient's name, participant number and date, without identifying the medication or placebo. The patient, surgeon, statistician and clinical staff entering data were not aware of treatment group allocation until all data were tabulated.

Treatment allocation involved either $3 \mathrm{~g}$ TXA in $50 \mathrm{~mL}$ saline, or $50 \mathrm{~mL}$ saline control, applied topically at the time of surgery. With open procedures (i.e., hemiarthroplasty), the solution was applied directly to the surgical wound and evacuated by suction after 3 minutes with no further wound irrigation. For percutaneous surgery (i.e., using cannulated screws, trochanteric fixation nails or intramedullary nails), a $13-\mathrm{cm} 13$-gauge Bard TruGuide coaxial biopsy needle (Becton Dickinson and Co.) was used to inject the fracture site via fluoroscopic guidance, and effort was made to aspirate the fluid after 3 minutes.

\section{Outcome measures}

Primary outcome measures included change in hemoglobin level from baseline on days 1,2 and 3 postoperatively, as well as transfusion of allogeneic blood. Blood transfusion triggers were established a priori, with 1 unit of packed red blood cells (pRBC) given to patients with a hemoglobin value less than $70 \mathrm{~g} / \mathrm{L}$, or a hemogloblin value less than $80 \mathrm{~g} / \mathrm{L}$ with symptoms of hypoperfusion (when the patient reported lightheadedness, chest pain or palpitations, experienced syncope or presyncope or sustained a myocardial infarction). Secondary outcome measures included allcause mortality at 90 days, incidence of VTE (symptomatic DVT proven by ultrasonography or pulmonary embolism diagnosed by computed tomographic angiography) at 30 days and perioperative complication rate (postoperative surgical site infection, ACS based on elevation of troponin I $>0.04$, or cerebrovascular accident [CVA]) at 30 days. Standard postoperative thromboprophylaxis was used for all patients as per institutional protocol (tinzaparin subcutaneously starting on postoperative day 1 ).

\section{Power calculation}

Power calculations were performed with primary and secondary outcome measures in mind. Assuming an 
$\alpha$ error of 0.05 , and 1 minus $\beta$ of 0.80 , we hypothesized that the average change in hemoglobin level for patients undergoing hip fracture surgery would be $40 \mathrm{~g} / \mathrm{L}$ (standard deviation [SD] $10 \mathrm{~g} / \mathrm{L}$ ). ${ }^{19}$ With the assumption that a $20 \%$ reduction in blood loss would be clinically significant (i.e., $8 \mathrm{~g} / \mathrm{L}$ ), 26 patients would be required in each group to detect a change. Given that ACS is 1 of the most common major complications of hip fracture surgery, with an anticipated incidence of $35 \%$ (SD 7\%), ${ }^{20}$ we felt that a $10 \%$ change in the incidence of ACS would be clinically significant. Assuming the same $\alpha$ and $\beta$ errors, 33 patients would be required in each group to detect a $10 \%$ change in cardiac complications.

\section{Statistical analysis}

Outcome assessment was performed according to intention-to-treat analysis. Continuous variables were summarized using means and ranges, while categorical variables were summarized using counts and proportions. The primary outcome was analyzed using repeatedmeasures multivariate analysis of variance (MANOVA), with baseline hemoglobin included as a covariate in the model. An identity contrast within the MANOVA platform was used to examine differences in hemoglobin (adjusted for baseline hemoglobin) between the groups at postoperative days 1,2 and 3 . The difference in the proportion of patients requiring a transfusion between the groups was analyzed using the Fisher exact test. The difference in total number of units of packed red blood cells transfused between the groups during the study was analyzed using Poisson regression to generate a $p$ value from the $\chi^{2}$ distribution. A post hoc sensitivity analysis on the primary outcome was performed using repeated-measures MANOVA with baseline hemoglobin, baseline estimated glomerular filtration rate (eGFR) and number of smokers included as covariates, because there was a higher proportion of smokers and a higher eGFR in the TXA group at baseline than in the control group. Secondary outcomes were analyzed using the Fisher exact test. All statistical analyses were preformed using JMP version 14.3.0 (SAS) using 2-tailed tests with $\alpha$ set to 0.05 .

\section{Results}

\section{Participants}

Of the 188 patients who were invited to participate in the study, 74 met the inclusion criteria. Nine of these patients were later excluded because it was realized that they met exclusion criteria (2 patients who had a history of DVT, 1 patient who had renal insufficiency, 3 patients who had ACS preoperatively, 2 patients for whom the medication was not delivered to the operating theatre by case end, and 1 patient who later declined surgery). These data are summarized in Figure 1.

The characteristics of the patients included in the analysis are presented in Table 1 . The baseline characteristics were similar between the groups, with the exception of renal function (higher GFR in the TXA group) and smoking status (41.9\% of the TXA group were smokers compared with $14.7 \%$ of the control group). None of the participants in the study were younger than 55 years of age, and none were highenergy polytrauma patients.

\section{Primary outcomes measures}

After controlling for baseline hemoglobin levels, we observed statistically significant differences in hemoglobin levels between the groups on postoperative day 1 of $7.09 \mathrm{~g} / \mathrm{L}(95 \%$ confidence interval [CI] 2.22 to $11.96 \mathrm{~g} / \mathrm{L}, p=0.005)$ and on postoperative day 2 of $9.04 \mathrm{~g} / \mathrm{L}$ ( $95 \%$ CI 3.53 to $14.55 \mathrm{~g} / \mathrm{L}, p=0.002$ ), but the difference failed to reach statistical significance by postoperative day $3(5.87 \mathrm{~g} / \mathrm{L}, 95 \% \mathrm{CI}-0.13$ to $11.86 \mathrm{~g} / \mathrm{L}$, $p=0.06$ ) (Figure 2). We found a $25 \%$ difference on day 1 (18 g/L TXA v. $24 \mathrm{~g} / \mathrm{L}$ control), a $26 \%$ difference on day $2(21.8 \mathrm{~g} / \mathrm{L}$ TXA, $29.6 \mathrm{~g} / \mathrm{L}$ control) and a $16 \%$ difference on day 3 (24.9 g/L TXA, $29.6 \mathrm{~g} / \mathrm{L}$ control). The overall mean difference in hemoglobin drop between the groups across the study was statistically significant in the repeated-measures MANOVA model $(p=0.004)$. There were no statistically significant differences identified within the groups over time ( $p$ values for time and the interactions between time and group and time and baseline hemoglobin level were all nonsignificant).

The percentage of patients requiring blood transfusion postoperatively did not differ significantly between the groups $(6.4 \%$ of the TXA group v. $14.7 \%$ of the control group, $p=0.43$ ) (Table 2). However, both of the patients in the TXA group who received transfusions received only 1 unit of $\mathrm{pRBC}$. Conversely, of the 5 patients in the control group who received blood, 1 received 3 units, while another received 2 units (the others each received 1 unit). The total number of transfused units of $\mathrm{pRBC}$ was significantly different between the groups $(p=0.024)$. However, the patient given 3 units of pRBC received 2 of the 3 units intraoperatively because of hemodynamic instability. This was before the administration of topical treatment. The administration of these 2 units of pRBC would therefore not have been influenced by whether the patient received TXA or placebo. When these 2 units are excluded from the analysis, the difference in the total number of units transfused between groups is no longer statistically significant $(p=0.07)$. 
A sensitivity analysis, which included baseline eGFR and smoking status along with baseline hemoglobin level as covariates in the repeated-measures MANOVA model, did not change the primary outcome results described above (data not shown).

\section{Secondary outcome measures}

The results of the analysis of secondary outcome measures are shown in Table 3. There were no statitiscally significant differences between the groups for any of the

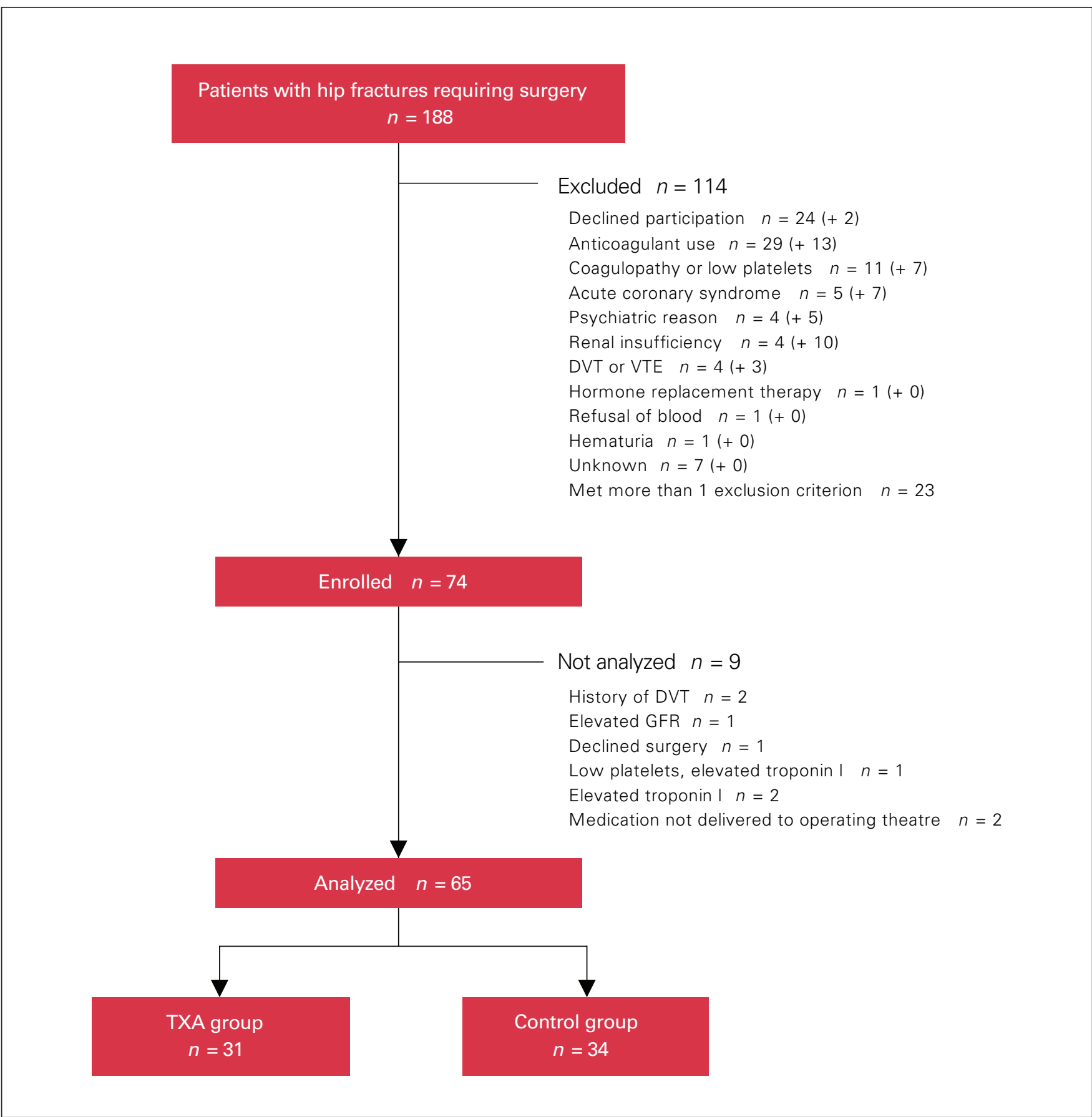

Fig. 1. Overview of study population. Consecutive patients presenting to Sault Area Hospital with hip fracture requiring surgery between November 2017 and February 2019 form the basis of the study. In the list of excluded patients, the values in parentheses indicate the number of patients who were excluded from the study for the listed reason but also met 1 or more additional exclusion criteria. For example, 24 patients were excluded from the study solely because they declined to participate; an additional 2 patients declined to participate and also met at least 1 other exclusion criterion. DVT = deep vein thrombosis; GFR $=$ glomerular filtration rate; TXA = tranexamic acid; VTE = venous thromboembolism. 


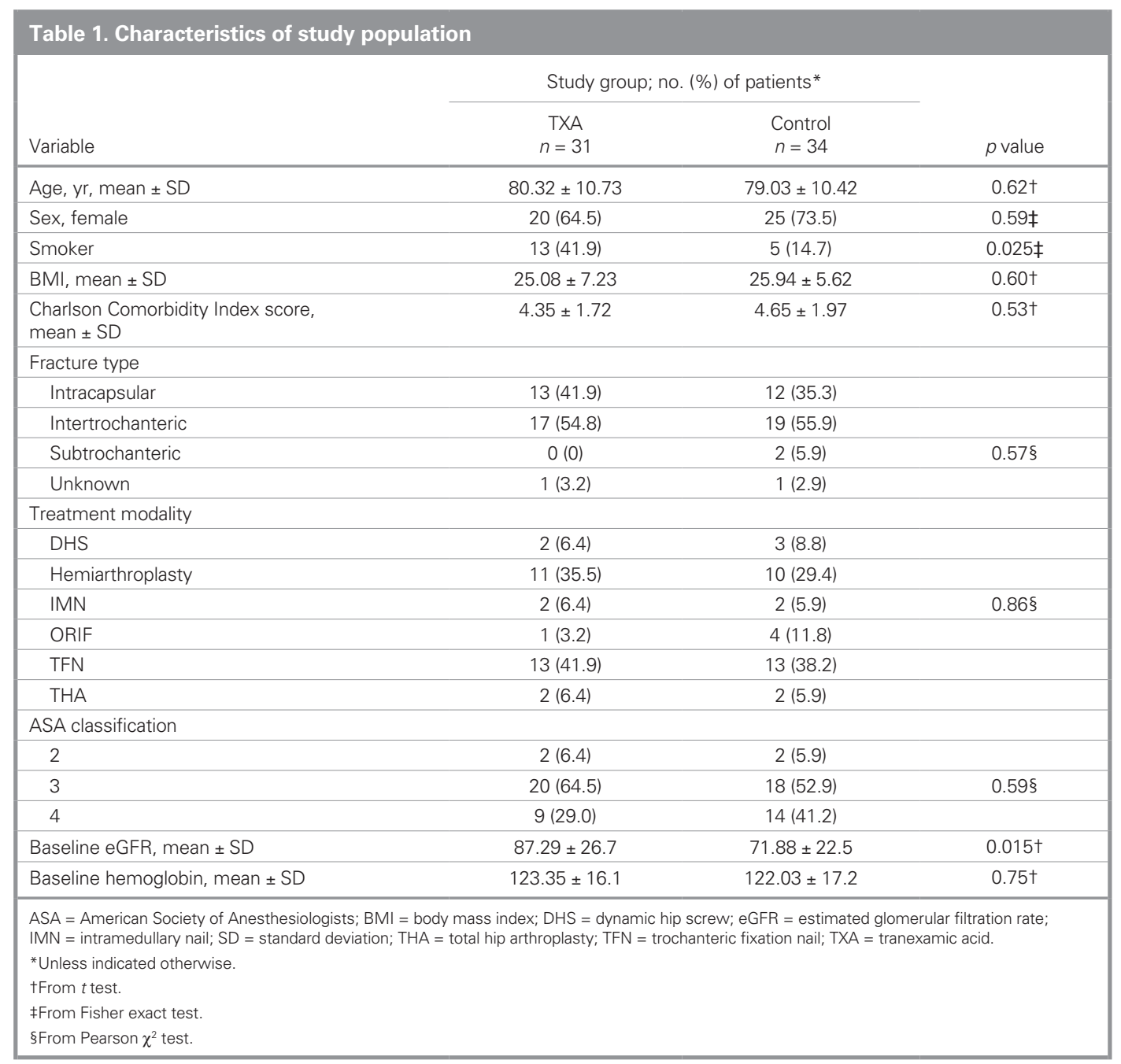

complications documented in the study, including ACS, CVA, VTE and 90-day mortality.

\section{Discussion}

This randomized, double-blinded, placebo-controlled trial demonstrated that topical TXA administered at the surgical site at the time of hip fracture surgery reduces early postoperative blood loss and exposure to allogenic blood. Whether the difference in blood loss between the groups is clinically significant remains in question. Our prestudy hypothesis was that a $20 \%$ reduction in blood loss would be clinically significant. We found a $25 \%$ difference on day 1 , a $26 \%$ difference on day 2 and a $16 \%$ difference on day 3 . In essence, the numerical difference in hemoglobin values between groups amounts to 1-2 units of pRBC..$^{21,22}$ Although preoperative anemia is a known predictor of slower recovery after hip fracture, ${ }^{23}$ and postoperative anemia after elective hip surgery predicts reduced mobility, ${ }^{24}$ the association between postoperative anemia and mobility is less certain with hip fractures. ${ }^{23,25}$ It has been previously documented that intravenous TXA is effective at reducing postoperative blood loss following hip fracture surgery. ${ }^{26-30}$ However, intravenous TXA has also been associated with cardiac and cerebrovascular events and increased mortality. ${ }^{11-13}$ Although underpowered to detect rare postoperative complications like CVA and death, our small, randomized study demonstrated that topical TXA reduces early postoperative drop in hemoglobin without increased risk.

The number of patients exposed to allogeneic blood did not differ significantly between the groups in this study. However, the number of units transfused was higher in the control group. One patient in the control group treated with an open approach to a subtrochanteric fracture received 2 units of blood intraoperatively outside of the transfusion parameters because of intraoperative hemodynamic instability. Although intraoperative bleeding would not be influenced by topical TXA administered at the completion of the surgery, inclusion of these 2 units of $\mathrm{pRBC}$ influenced our results (when the 2 units of pRBC transfused intraoperatively 


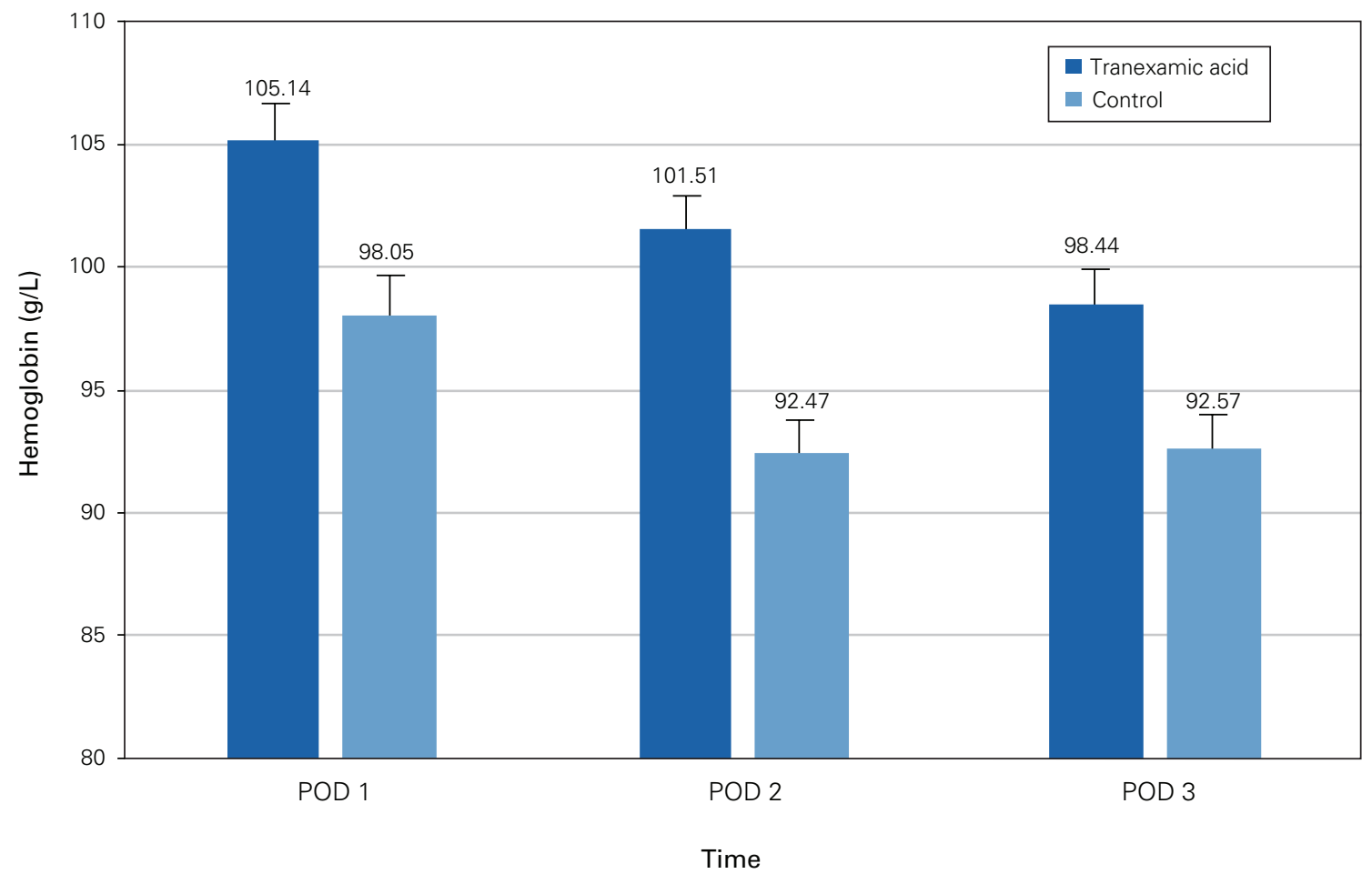

Fig. 2. Adjusted hemoglobin levels on POD 1, 2 and 3 after hip fracture surgery. For POD 1, $p=0.005$. For POD 2, $p=0.02$. For POD 3 , $p=0.06$. POD $=$ postoperative day.

\begin{tabular}{|c|c|c|c|}
\hline Variable & $\begin{array}{c}\text { TXA } \\
n=31\end{array}$ & $\begin{array}{l}\text { Control } \\
n=34\end{array}$ & $p$ value \\
\hline Transfusion, no. (\%) & $2(6.4)$ & $5(14.7)$ & $0.43+$ \\
\hline $\begin{array}{l}\text { Total no. of units of pRBC } \\
\text { transfused }\end{array}$ & 2 & $8 \neq$ & $0.024 \S$ \\
\hline \multicolumn{4}{|c|}{$\mathrm{pRBC}=$ packed red blood cells; TXA = tranexamic acid } \\
\hline \multicolumn{4}{|c|}{$\begin{array}{l}{ }^{*} \text { All patients receiving blood after study enrolment were included. Transfusion trigger } \\
\text { parameters were hemoglobin level less than } 70 \mathrm{~g} / \mathrm{L} \text {, or hemogloblin level less than } 80 \mathrm{~g} / \mathrm{L} \\
\text { with symptoms of hypoperfusion. }\end{array}$} \\
\hline \multicolumn{4}{|c|}{ †From Fisher exact test. } \\
\hline \multicolumn{4}{|c|}{$\begin{array}{l}\ddagger \text { One patient in the control group who had a subtrochanteric fracture required an open } \\
\text { reduction and received } 2 \text { units of } \mathrm{pRBC} \text { intraoperatively because of hemodynamic instability } \\
\text { (i.e., outside of the transfusion parameters), followed by } 1 \text { unit of pRBC on postoperative } \\
\text { day } 1 \text {. When the } 2 \text { units of pRBC given intraoperatively are excluded, the numbers of units } \\
\text { transfused between the groups are no longer significantly different ( } p=0.07 \text { ). }\end{array}$} \\
\hline$\S$ From $\chi^{2}$ test. & & & \\
\hline
\end{tabular}

are excluded, the number of transfused units fails to reach statistical significance $[p=0.07])$. We designed the study with an intention-to-treat analysis, and therefore these data were included in our analysis. We anticipated a higher transfusion rate in our study on the basis of prior studies. ${ }^{7-9}$ Our low transfusion rate may have been influenced by our restrictive protocol established a priori, which we chose to reduce postoperative complications with hip fracture surgery. ${ }^{31}$

Prior studies have determined that the cost of each unit of blood transfused amounts to approximately \$1800-\$2600 in the United States. ${ }^{32}$ The fact that this

\begin{tabular}{|c|c|c|c|}
\hline \multirow[b]{2}{*}{ Outcome } & \multicolumn{2}{|c|}{$\begin{array}{l}\text { Study group; no. (\%) of } \\
\text { patients }\end{array}$} & \multirow[b]{2}{*}{$p$ value* } \\
\hline & $\begin{array}{c}\text { TXA } \\
n=31\end{array}$ & $\begin{array}{l}\text { Control } \\
n=34\end{array}$ & \\
\hline VTE† & $0(0)$ & $1(2.9) \ddagger$ & 1.00 \\
\hline Perioperative ACS & $1(3.2)$ & $4(11.8)$ & 0.36 \\
\hline Perioperative CVAt & $0(0)$ & $0(0)$ & NA \\
\hline $\begin{array}{l}\text { Postoperative surgical site } \\
\text { infectiont }\end{array}$ & $1(3.2)$ & $0(0)$ & 0.48 \\
\hline $\begin{array}{l}\text { All-cause mortality at } 90 \mathrm{~d} \\
\text { postoperatively }\end{array}$ & $2(6.4)$ & $1(2.9)$ & 0.60 \\
\hline \multicolumn{4}{|c|}{$\begin{array}{l}\text { ACS = acute coronary syndrome; } \mathrm{CVA}=\text { cerebrovascular accident; } \mathrm{DVT}=\text { deep vein } \\
\text { thrombosis; } \mathrm{NA}=\text { not applicable; } \mathrm{TXA}=\text { tranexamic acid; } \mathrm{VTE}=\text { venous thromboembolism. } \\
\text { *From Fisher exact test. } \\
\text { tAll complications were recorded up to } 30 \text { days postoperatively. } \\
\text { fDenotes } 1 \text { case of DVT in the control group. }\end{array}$} \\
\hline
\end{tabular}

small study resulted in a trend toward a $67 \%-75 \%$ reduction in units of blood transfused with topical TXA suggests that there may be considerable savings to the health care system, without accounting for the fact that allogenic blood transfusions are an independent predictor of prolonged hospital length of stay. ${ }^{10}$ Given the observed transfusion incidence in this study, our power calculations were inaccurate, and it is anticipated that a larger study group would be required to reach statistical significance. 
Interesting secondary findings of this study included the number of patients who developed an ACS around the time of hip fracture: 3 of the 74 enrolled patients were later excluded (before drug administration) because ACS was recognized preoperatively, and 5 of the 65 patients for whom data were analyzed developed ACS during the study. Although this is a lower rate of ACS than reported in other studies, ${ }^{20}$ it reminds us of the frailty of the hip fracture population. While a low hemoglobin level is associated with a higher risk of ACS after hip fracture, ${ }^{33}$ there is also a theoretical concern that TXA may increase the risk of myocardial infarction because of reduced clot breakdown. In this small study, there was no significant difference in ACS incidence between groups $(3.2 \%$ v. $11.8 \%)$. Although this may have been influenced by our exclusion criteria (history of ACS within 6 mo of presentation), this possibility warrants further study with a larger population.

Strengths of this study include the randomized, double-blinded and placebo-controlled design, aimed at minimizing bias. Further, a variety of hip fractures were included, which makes the findings generalizable to most hip fractures managed with multiple techniques. Unfortunately, there were only 2 subtrochanteric hip fractures in the study, both of which were in the control group, which means that we were unable to draw any conclusion regarding the efficacy of topical TXA in this subtype of hip fracture. In addition, the blood transfusion criteria were established a priori with the goal of reducing surgeon-to-surgeon variability in transfusion triggers. There were 6 surgeons participating in patient care, who may have had practice differences in terms of fracture management (i.e., intramedullary nail v. dynamic hip screw or hemiarthroplasty v. total hip arthroplasty), which again enhances the generalizability of our findings.

\section{Limitations}

Weaknesses of this study include the relatively small number of patients. This study was performed at a small community hospital that typically manages between 150 and 200 hip fractures per year. Our exclusion criteria were designed to ensure patient safety, but unfortunately this makes the applicability of the results to all frail elderly patients with hip fracture less certain. Although we hypothesize that less blood loss postoperatively can on its own be cardioprotective, a larger study including patients with some of our exclusion criteria would make our findings more generalizable to the typical patient presenting with hip fracture. This could form the basis of a multicentre study with less stringent exclusion criteria. Further, it has been suggested recently that TXA can be cytotoxic to human chondrocytes. $^{34,35}$ Although this recent finding would limit the feasibility of using topical TXA around articular cartilage, it is noteworthy that the dose used in this study as well as the duration of exposure is considerably lower than in the above studies. Further, TXA-induced chondrocyte toxicity is not uncontested in the literature, with shorter duration of exposure at typical treatment doses revealing no chondrocyte toxicity. ${ }^{36,37}$

\section{Conclusion}

Topical TXA reduces early perioperative blood loss without increasing complications in patients undergoing surgery for a hip fracture. Routine addition of this 3-minute step to the surgical management of hip fractures may help minimize perioperative blood loss in this frail population.

Acknowledgements: This study would not have been possible without the dedication of Megan Gray and Emily Elder, who collected the data and performed the chart review. Thanks to Michael Costain, who assisted with institutional approval and performed the groundwork before study initiation. Travis Quevillon kindly volunteered his time to assist with ensuring data integrity and making protocol changes to the study. Natalie Walde was instrumental in assisting with obtaining Health Canada approval and ethics approval, registering the study with ClinicalTrials.gov, overseeing the integrity of the data and managing the finances. Drs. Best, Hill and Spadafora generously donated their time to evaluate the mid-term data to ensure the study was not placing our patients at risk.

Affiliations: From the Northern Ontario School of Medicine, Sault Ste. Marie, Ont. (Costain, Elder, Kelly, Cheong, Fera); and the Sault Area Hospital, Sault Ste. Marie, Ont. (Costain, Elder, Fraser, Slagel, Kelly, Cheong, Fera).

Funding: This study was supported by grants from the Northern Ontario Academic Medicine Association and the Sault Ste. Marie Academic Medical Association.

Competing interests: None declared.

Contributors: D. Costain, G. Elder and B. Slagel designed the study. D. Costain, G. Elder, B. Fraser, A. Kelly, Y. Cheong and L. Fera acquired the data, which D. Costain and L. Fera analyzed. D. Costain, G. Elder and L. Fera wrote the article, which all authors critically reviewed. All authors gave final approval of the version to be published.

Content licence: This is an Open Access article distributed in accordance with the terms of the Creative Commons Attribution (CC BYNC-ND 4.0) licence, which permits use, distribution and reproduction in any medium, provided that the original publication is properly cited, the use is noncommercial (i.e., research or educational use), and no modifications or adaptations are made. See: https://creativecommons. org/licenses/by-nc-nd/4.0/

\section{References}

1. Canadian Institute for Health Information. Seniors and falls update sheet. CIHI National Trauma Registry. Ottawa: Canadian Institute for Health Information; 2010. Available: www.cihi.ca/CIHI-extportal/ pdf/internet/SENIORS_FALLS_INFO_EN (accessed 2015 Jan. 31).

2. Canadian Institute for Health Information. Hip and knee replacements in Canada: Canadian Foint Replacement Registry 2014 annual report. Ottawa: Canadian Institute for Health Information; 2014.

3. Radcliff TA, Henderson WG, Stoner TJ, et al. Patient risk factors, operative care, and outcomes among older community-dwelling male veterans with hip fracture. 7 Bone foint Surg 2008;90:34-42. 
4. Sarimo S, Pajulammi H, Jamsen E. Process-related predictors of readmissions and mortality following hip fracture surgery: a population-based analysis. Eur Geriatr Med 2020;11:613-622.

5. Costain DJ, Whitehouse SL, Pratt NL, et al. Perioperative mortality after hemiarthroplasty related to fixation method. Acta Orthop 2011;82:275-81.

6. Elder GM, Harvey EJ, Vaidya R, et al. The effectiveness of orthopaedic trauma theatres in decreasing morbidity and mortality: a study of 701 displaced subcapital hip fractures in two trauma centres. Injury 2005;36:1060-6.

7. Desai SJ, Wood KS, Marsh J, et al. Factors affecting transfusion requirement after hip fracture: Can we reduce the need for blood? Can 7 Surg 2014;57:342-8.

8. Kadar A, Chechik O, Steinberg E, et al. Predicting the need for blood transfusion in patients with hip fractures. Int Orthop 2013;37:693-700.

9. Madsen CM, Jorgensen HL, Norgaard A, et al. Preoperative factors associated with red blood cell transfusion in hip fracture patients. Arch Orthop Trauma Surg 2014;134:375-82.

10. Vochteloo AJ, Borger van der Burg BL, Mertens B, et al. Outcome in hip fracture patients related to anemia at admission and allogeneic blood transfusion: an analysis of 1262 surgically treated patients. BMC Musculoskelet Disord 2011;12:262-9.

11. Emara WM, Moez KK, Elkhouly AH. Topical versus intravenous tranexamic acid as a blood conservation intervention for reduction of post-operative bleeding in hemiarthroplasty. Anesth Essays Res 2014;8:48-53.

12. Zufferey PJ, Miquet M, Quenet $S$, et al. Tranexamic acid in hip fracture surgery: a randomized controlled trial. Br 7 Anaesth 2010;104:23-30.

13. Tengberg PT, Foss NB, Palm H, et al. Tranexamic acid reduces blood loss in patients with extracapsular fractures of the hip. Results of a randomized controlled trial. Bone foint 7 2016;98B:747-53.

14. Soni A, Saini R, Gulati A, et al. Comparison between intravenous and intra-articular regimes of tranexamic acid in reducing blood loss during total knee arthroplasty. F Arthroplasty 2014;29:1525-7.

15. Gomez-Barrena E, Ortega-Andreu M, Padilla-Eguiluz NG, et al. Topical intra-articular compared with intravenous tranexamic acid to reduce blood loss in primary total knee replacement, a doubleblind, randomized, controlled, noninferiority clinical trial. $\mathcal{F}$ Bone foint Surg 2014;96:1937-44.

16. Gilbody J, Dhotar HS, Perruccio AV, et al. Topical tranexamic acid reduces transfusion rates in total hip and knee arthroplasty. 7 Arthroplasty 2014;29:681-4.

17. Patel JN, Spanyer JM, Smitl LS, et al. Comparison of intravenous versus topical tranexamic acid in total knee arthroplasty: a prospective randomized study. F Artbroplasty 2014;29:1528-31.

18. Wong J, Abrishami A, El-Beheiry H, et al. Topical application of tranexamic acid reduces postoperative blood loss in total knee arthroplasty. $\mathcal{F}$ Bone foint Surg 2010;92:2503-13.

19. Smeets SJM, Verbruggen JPAM, Poeze M. Effect of blood transfusion on survival after hip fracture surgery. Eur 7 Orthop Surg Traumatol 2018;28:1297-1303.

20. Hietala P, Strandberg M, Kiviniemi T, et al. Usefulness of troponin $\mathrm{T}$ to predict short-term and long-term mortality in patients after hip fracture. Am 7 Cardiol 2014; 114:193-7.
21. Kashefi P, Rahmani A, Khalifesoltani M. Changes in the hemoglobin level after one unit of packed red blood cell transfusion in intensive care unit patients. F Res Med Sci 2018;23:85.

22. Lee JH, Kim DH, Kim K, et al. Predicting change of hemoglobin after transfusion in hemodynamically stable anemic patients in emergency department. 7 Trauma 2010;68:337-41.

23. Sim YE, Sim SD, Seng C, et al. Preoperative anemia, functional outcomes, and quality of life after hip fracture surgery. $7 \mathrm{Am}$ Geriatr Soc 2018;66:1524-31.

24. Jans Ø, Bandholm T, Kurbegovic S, et al. Postoperative anemia and early functional outcomes after fast-track hip arthroplasty: a prospective cohort study. Transfusion 2016;56:917-25.

25. Hulsbæk S, Larsen RF, Troelsen A. Predictors of not regaining basic mobility after hip fracture surgery. Disabil Rebabil 2015;37:1739-44.

26. Watts CD, Houdek MT, Sems SA, et al. Tranexamic acid safely reduced blood loss in hemi- and total hip arthroplasty for acute femoral neck fracture: a randomized clinical trial. 7 Orthop Trauma 2017;31:345-51.

27. Jiang $W$, Shang L. Tranexamic acid can reduce blood loss in patients undergoing intertrochanteric fracture surgery: a metaanalysis. Medicine (Baltimore) 2019;98:1-11.

28. Qi YM, Wang HP, Li YJ, et al. The efficacy and safety of intravenous tranexamic acid in hip fracture surgery: a systematic review and meta-analysis. F Orthop Translat 2019;19:1-11.

29. Cheung ZB, Anthony SG, Forsh DA, et al. Utilization, effectiveness, and safety of tranexamic acid use in hip fracture surgery: a population-based study. 7 Orthop 2020;20:167-72.

30. Zhou XD, Zhang Y, Jiang LF, et al. Efficacy and safety of tranexamic acid in intertrochanteric fractures: s single-blind randomized controlled trial. Orthop Surg 2019;11:635-42.

31. Amin RM, DeMario VM, Best MJ, et al. A restrictive hemoglobin transfusion threshold of less than $7 \mathrm{~g} / \mathrm{dL}$ decreases blood utilization without compromising outcomes in patients with hip fractures. 7 Am Acad Orthop Surg 2019;27:887-94.

32. Basha J, Dewitt R, Cable D, et al. Transfusions and their costs: managing patient needs and hospitals economics. Int 7 Emerg Intensive Care Med 2005;9:2.

33. Huddleston JM, Gullerud RE, Smither F, et al. Myocardial infarction after hip fracture repair: a population-based study. 7 Am Geriatr Soc 2012;60:2020-6.

34. Jacob B, Kloss N, Böhle S, et al. Tranexamic acid is toxic on human chondrocytes, in vitro. 7 Orthop 2019;20:1-5.

35. McLean M, McCall K, Smith IDM, et al. Tranexamic acid toxicity in human periarticular tissues. Bone foint Res 2019;8:11-8.

36. Goderecci R, Giusti I, Necozione S, et al. Short exposure to tranexamic acid does not affect, in vitro, the viability of human chondrocytes. Eur 7 Med Res 2019;24:15.

37. Marmotti A, Mattia S, Mangiavini L, et al. Tranexamic acid effects on cartilage and synovial tissue: an in vitro study for a possible safe intra-articular use. 7 Biol Regul Homeost Agents 2016;30:33-40. 